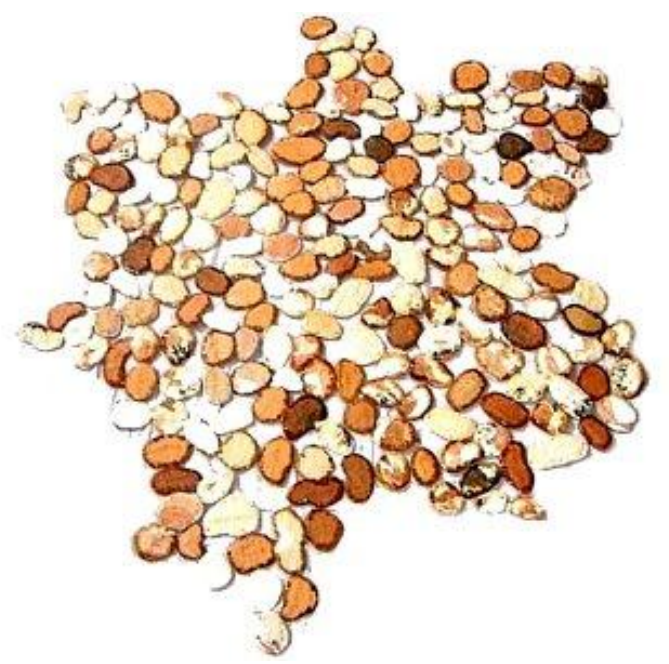

\title{
Transbordamentos: a estética das correspondências na construção do livro-objeto
}

Wanêssa Cristina Vieira Cruz

Wanêssa Cristina Vieira Cruz é escultora e ceramista Graduada em Artes Plásticas e PósGraduada em Arte e Contemporaneidade pela Escola Guignard - UEMG.

\section{Resumo}

"Transbordamentos" é uma tessitura da obra Grande sertão: veredas, de João Guimarães Rosa, em que diversos personagens, topos geográficos 
e eventos inscritos sobre fragmentos de cerâmica vão se conectando por meio de laçadas e nós. A feitura dessa produção plástica possibilitou uma reflexão transdisciplinar em que arte, literatura e filosofia se articulam num constante intercruzamento, cujo jogo combinatório vai compondo outro Grande Sertão. Essa trama se fundamenta no conceito de rizoma, a partir de Deleuze e Guattari.

Palavras-chave: fragmento, tessitura, rizoma.

\section{Transbordamentos - um olhar transdisciplinar}

Inúmeras são as leituras de Grande sertão: veredas, de João Guimarães Rosa. Conforme disse Antonio Candido,

Cada um poderá abordá-la a seu gosto, conforme o seu ofício; mas em cada aspecto aparecerá o traço fundamental do autor: a absoluta confiança na liberdade de inventar(1).

"Transbordamentos" é o tecido de uma trama. Livro não-códice remetendo à idéia de livrorizoma a partir dos conceitos de Deleuze e Guattari.

Esta produção plástica justifica-se como um trabalho transdisciplinar, uma vez que se propõe a ser pensada como uma rede. Sua criação só foi possível devido à contribuição de diversas áreas, experiência que se concretizou devido à aproximação entre distintos campos do conhecimento: filosofia, literatura e "artes, que também é um saber" (2) . 
Txt: Leituras Transdisciplinares de Telas e Textos, Belo Horizonte, n. 3, p. 30-48, 2006.

Segundo Hugo Assmann,

a transdisciplinaridade não pretende desvalorizar as competências disciplinares específicas. Ao contrário, pretende elevá-las a um patamar de conhecimentos melhorados nas áreas disciplinares, já que todas elas devem embeber-se de uma nova consciência epistemológica, admitindo que é importante que determinados conceitos fundantes possam transmigrar através (trans) das fronteiras disciplinares(3).

Olhares cruzados, olhares transdisciplinares. A tessitura do sertão possibilitando que, por meio do afrouxamento de fronteiras disciplinares, da ocupação de zonas de indefinição, dos interstícios disciplinares, as referências cruzadas, sem qualquer idéia de hierarquia, organizem-se em torno de uma tópica de atravessamentos e transbordamentos.

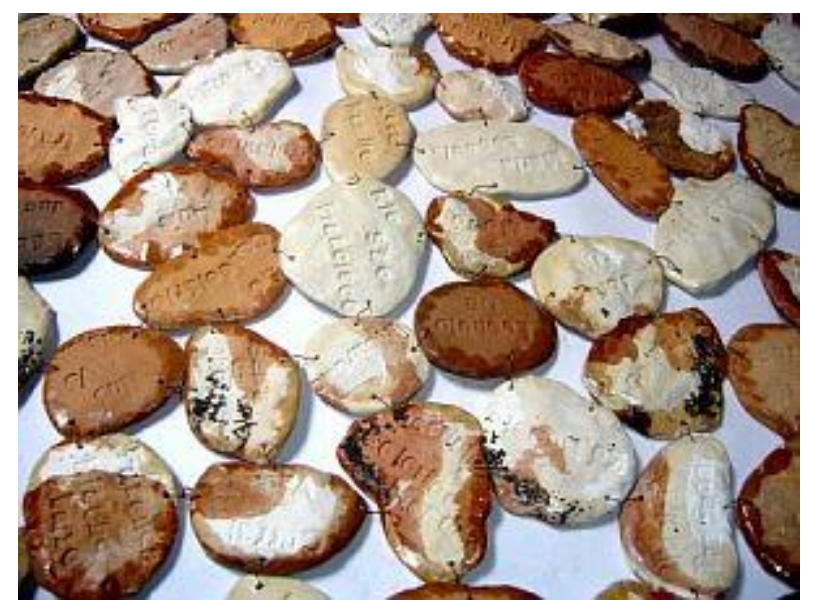

\section{De sua feitura}

"Transbordamentos" nasce na palma de minha mão. o gesto de amassar a argila, utilizando como molde a sua própria concavidade, sintetiza o princípio da modelagem-moldagem, no sentido de 
se trabalhar a partir de um molde. A argila, matéria inerte e amorfa, corporifica-se no instante em que a mão conjuga o acaso da matéria. Um simples gesto meu e ela se insere dentro do princípio das metamorfoses. No instante em que a mão toca a matéria, estrutura uma forma por meio do gesto metamórfico; o gesto multiplica as formas e expõe um conteúdo significativo.

Esta produção plástica é um trabalho de textura, que deve ser compreendido como "ato ou efeito de tecer, o tecido, a trama, a união intima das partes de um corpo, uma contextura, a ligação ou o arranjo das partes de uma obra" (4) .

Estruturalmente, o trabalho apresenta-se como uma trama em que fragmentos de cerâmica e fios se entrelaçam. A obra constrói-se por meio da reprodutibilidade do gesto e se multiplica pela ação reiterada. As unidades vão se conectando por meio de um fio e compondo uma trama. Esse fio condutor é o indício que serve de guia - o elemento responsável por sua expansão no espaço. Fragmentos conectando-se, fazendo surgir formas e criando novos significados.

Os significados vão sendo atribuídos, na medida em que a matéria vai adquirindo forma; então a matéria argila deixa de ser um fato meramente físico e passa a adquirir uma materialidade plena de significados, sendo formada e transformada pelo homem com toda a sua carga de conhecimentos e emoções(5).

\section{Laçadas e nós}

Laçada, o primeiro movimento para se dar um nó, é considerado por Ítalo Calvino como 
Txt: Leituras Transdisciplinares de Telas e Textos, Belo Horizonte, n. 3, p. 30-48, 2006.

a interseção de duas curvas (...) o ponto onde se escorre, gira ou flui ou perpassa ou se enlaça uma ponta de corda ou se corta ou se escalda o fio ou a linha ou o barbante ou o cordão, (...) a arte de fazer os nós, ponto culminante de ambas - a abstração mental e a habilidade manual - poderia ser vista como a característica humana por excelência, tanto quanto e talvez ainda mais que a linguagem(6) .

Em toda essa produção plástica, a linha se fez presente. Segmento mensurável, ao percorrer um trajeto, ele vai construindo um espaço. Enquanto costura, expande-se no espaço. O fio a linha que costura - é vínculo, é ponte. Une, sustenta o trabalho e constrói a obra. Fragmento por fragmento, em seqüência, multiplicando-se, articulando-se.

A palavra latina ars, matriz do português arte, está na raiz do verbo "articular", que denota a ação de fazer junturas entre as partes de um todo(7).

Os fragmentos, ao serem articulados, vão produzindo espaços vazios, trazendo um aspecto arejado ao trabalho. Como conseqüência desse procedimento, percebo uma conexão com aquilo que Barthes denominou de

um estado: o Raro. Rarus, em latim, significa "aquilo que apresenta intervalos, interstícios, que é espaçado, poroso, esparso"(8).

A obra é tecida segundo o princípio do Raro, isto é, do espaçamento. Esse espaço vazio foi gerado pelo acaso "(tyché) que em grego, é o acontecimento que sobrevém por acaso" (9). O espaço negativo proporcionado pelo acaso das articulações gerou uma certa transparência e me remeteu a um rizoma. 
Txt: Leituras Transdisciplinares de Telas e Textos, Belo Horizonte, n. 3, p. 30-48, 2006.

"Transbordamentos" é uma criação que ganhou vida dentro da especificidade da argila. A superfície da trama é como um território híbrido que, de acordo com Ricardo Basbaum, representa a relação entre duas trajetórias em que

enunciados e visibilidades confrontam-se num mesmo tempo e num mesmo espaço, em ação mútua e combinada. (...) Signo plástico e enunciado verbal aproximam-se do mesmo instante, partes simultâneas e diferenciadas do mesmo processo: o enunciado criativo e seu espaço próprio deslocam-se para o interior da obra(10).

Dentro desse conceito, objeto e significado entrelaçam-se. A obra constrói-se tecendo uma rede de significados e, em contínua tessitura, ganha corporalidade no espaço. E, nessa contextura, vai sendo construída como a "disposição e união das partes constituintes de um todo, caráter estrutural de qualquer coisa, corpo ou estrutura resultantes do entrelaçamento ou ligação de partes"(11). A organicidade gerada pelas articulações quebra o aspecto rígido da cerâmica.

Tecendo, fiando, articulando, por meio de uma contínua tessitura, "Transbordamentos" vai se desenvolvendo como uma rede rizomática. No Dicionário Universal da Língua Portuguesa, o vocábulo "rizoma" vem do grego, rhízoma: "raiz, caule subterrâneo horizontal"(12). No dicionário Michaelis, a definição do termo se amplia: "ri.zo.ma s.m.. Bot. (rizo+ma), caule subterrâneo, no todo ou em parte, de crescimento horizontal"(13). Na Botânica, o termo foi definido por Damião Filho. O aspecto forte da metáfora consiste na maior liberdade auto-organizativa das formas do saber 
(conceitos, linguagens, articulações do sentido). As várias articulações permitem uma expansão versátil em diversas direções.

Rizomas são sistemas acentrados, nãohierárquicos, que realizam conexões, ligamentos e junções. Rizoma é aliança, movimento transversal, direção perpendicular. Procede por variação, expansão, conquista, captura. "Um rizoma não começa nem conclui, ele se encontra no meio, entre as coisas, inter-ser, intermezzo" (14).

Segundo Pierre Lévy, a rede não tem centro, ou melhor, possui diversos centros perpetuamente móveis, saltando de um nó a outro, trazendo ao redor de si uma ramificação infinita de pequenas raízes, de rizomas.

\section{o Grande sertão: um rizoma}

"Transbordamentos" é uma tessitura do Grande sertão: veredas. E, como texto, a melhor maneira de compreendê-lo é recortando-o em termos do que nos pareça mais significante: personagens, eventos, geografias diversas, expressões regionais, e criando outros similares ao sertão que ora se apresenta.

Como texto, fundamenta-se no conceito de rizoma, que são raízes interligadas sem um ponto de convergência. Gilles Deleuze e Félix Guattari, em Mil platôs, partem da metáfora vegetal do rizoma e a transformam em conceito filosófico. Pressupõem um processo que pode ser distinguido por um conjunto de "características aproximativas", estabelecendo princípios como conexão e heterogeneidade, multiplicidade, 
Txt: Leituras Transdisciplinares de Telas e Textos, Belo Horizonte, n. 3, p. 30-48, 2006.

ruptura a-significante, cartografia e decalcomania.

"A primeira e mais óbvia propriedade de qualquer rede é sua não-linearidade - ela se estende em todas as direções".(15) As redes de comunicação podem gerar laços de realimentação; por essa razão, podem adquirir a capacidade de regular a si mesmas - a auto-organização que se define como "a interconectividade não-linear dos componentes do sistema"(16)

Grande sertão: veredas é o melhor exemplo de rede que se propaga a partir de cada um dos elementos que constituem o romance "como enciclopédia, como método de conhecimento, e principalmente como rede de conexões entre os fatos, entre as pessoas, entre as coisas do mundo" (17). Como todo texto literário, contém um modelo do universo, sendo o melhor atributo do universo - o infinito, o inumerável.

O princípio das redes dos possíveis se insere em todo o extenso romance. De estrutura combinatória, ele é uma somatória de histórias que se intercruzam. Grande sertão: veredas é a melhor apologia do romance como grande rede: uma obra que tende para a multiplicidade dos possíveis.

Percebo "Transbordamentos" como uma autopoiese, termo cunhado pelos chilenos Humberto Maturana e Francisco Varela, ambos neurocientistas. Auto significa "si mesmo" e se refere à autonomia dos sistemas auto-organizados, e poiese - que compartilha da mesma raiz grega da palavra "poesia" - significa "criação", "construção" . Portanto, autopoiese significa 
"autocriação"(18). Um sistema é autopoiético quando é constituído por um conjunto de componentes cujas transformações e interações não cessam de reproduzir a organização, sendo um sistema que produz a si mesmo.

Embora a noção de autopoiese se aplique somente a sistemas moleculares vivos, é possível imaginar sistemas autopoiéticos nãomoleculares. Assim, diz Maturana, "é possível que uma cultura seja um sistema autopoiético, que existe em um espaço de conversações, porém é uma cultura, não um ser vivo"(19).

Essa expressão, neste trabalho, tem um sentido metafórico. Trata-se de uma rede de processos de produção onde cada componente participa da produção ou transformação de outros componentes da rede. Assim, a rede produz a si mesma continuamente.

"Transbordamentos" configura-se como um território heterogêneo, onde encontramos múltiplas e crescentes relações. Aqui, aplicase o princípio da conexão e da heterogeneidade. o rizoma opõe-se à idéia de hierarquia, pois ao contrário da estrutura de uma árvore, em tese, ele pode conectar qualquer ponto a qualquer outro, oferecendo muitos começos e muitos fins. A exemplo de uma rede aberta, um rizoma está sempre no meio, não tem começo nem fim, transborda e implica a idéia de infiltração, de um escoamento que preenche vazios.

Tessitura descentralizada, conectando pontos ordinários, criando territorialização e desterritorialização sucessivas. Multiplica-se de forma extensa e anárquica, sem que se 
estabeleça uma ordem, a partir de conexões múltiplas e diferenciadas. Cada nó, cada laçada - uma conexão. As conexões rizomáticas caracterizam-se como sistemas complexos autoorganizados. O rizoma tem como tecido a conjunção e. Diversos personagens, geografias e eventos se articulam num constante intercruzamento. Elos se conectam e, num jogo combinatório, vão compondo o grande sertão.

Nesse sistema a-centrado a comunicação ocorre de vizinho a qualquer vizinho, nos quais os elementos são todos intercambiáveis, de tal maneira que o resultado final global se sincroniza independente de uma instância central.

Também a lógica da multiplicidade se insere em "Transbordamentos". Cada elemento, por menor que seja dentro do romance, estabelece uma rede de relações, multiplicando os detalhes a ponto de suas descrições e divagações se tornarem infinitas.

De qualquer ponto que parta, o discurso se alarga de modo a compreender horizontes sempre mais vastos e, se pudesse se desenvolver em todas as direções, acabaria por abraçar o universo inteiro(20).

Um texto como esse se constitui de multiplicidades lineares, sendo feito somente de linhas: linhas de segmentaridade, linhas de fuga. Movimento transversal, direção perpendicular. Procede por variação, expansão, conquista, captura. Oposto ao grafismo, aos decalques, refere-se a um mapa que deve ser produzido, sempre desmontável, reversível, modificável, com múltiplas entradas e saídas. Cada elemento que compõe Grande sertão: veredas 
se configura como um fragmento e este se caracteriza num platô que se situa sempre no meio. Platô, segundo Deleuze e Guattari, é "toda multiplicidade conectável com outras hastes subterrâneas superficiais de maneira a formar e estender um rizoma"(21). Também esse rizoma se constitui de platôs.

"Transbordamentos" também pode ser percebido dentro do princípio da ruptura a-significante. Topos geográficos, acontecimentos, personagens - cada elemento-fragmento "pode ser rompido, quebrado em um lugar qualquer"(22) .

Haverá ruptura no rizoma sempre que linhas de segmentaridade explodirem em linhas de fuga; "estas linhas não param de se remeter umas às outras" (23).

Do ponto de vista deleuziano, "Transbordamentos" poderá ser abordado como um mapa. "Um mapa é uma questão de performance" (24). É produção, é registro de caminho. É aberto, conectável em todas as suas dimensões, desmontável, alterável, reversível, susceptível de receber modificações e adaptarse a montagens distintas. Uma de suas características é a de possuir múltiplas entradas. Contribui, assim, para a conexão dos campos.

\section{A estética da correspondência: poética analogia}

A poética de Guimarães Rosa, por se encontrar muito próxima da visualidade, desperta para um interessante jogo de relações entre texto e imagem. A força da palavra em Grande sertão: 
Txt: Leituras Transdisciplinares de Telas e Textos, Belo Horizonte, n. 3, p. 30-48, 2006.

veredas suscita com vigor a imaginação que se traduz em luz, sombras, texturas, timbres, ritmos e movimentos. O texto literário é percebido como um mar de possibilidades de transcriações articuladas que se encontram dispersas pelo texto literário, que são afins ao tema e de onde partirá o livro-rizoma.

O poético para Barthes é:

a capacidade simbólica de uma forma; esta capacidade só tem valor se permite à forma "partir" para um grande número de direções e manifestar, assim, potencialmente, - infinito caminho do símbolo, de que nunca se pode fazer um significado último e que é, em suma, sempre o significante de um outro significante (razão pela qual o verdadeiro antônimo do poético é o estereotipado) (25).

$\mathrm{Na}$ visão de Regis Debray, "o símbolo é um objeto convencional que tem como razão de ser o acordo dos espíritos e a reunião dos sujeitos. Simbolizar é reunir, colocar junto, aproximar" (26).

Paul Valéry parte da etimologia da palavra, associando poética ao radical grego poiein, o fazer (obras de espírito). Para o autor "Poesia é a arte da linguagem em que certas combinações de palavras podem produzir uma emoção; a isso denomina-se poética"(27). Assim definido, o universo poético apresenta grandes analogias com o universo do sonho. Valéry compreende a analogia como "a faculdade de variar as imagens, combiná-las, fazer coexistir a parte de uma com a parte da outra e perceber as ligações de suas estruturas"(28).

Octavio Paz considera a analogia a "estética da correspondência entre todos os seres e os 
mundos"(29). Para o autor, a analogia concebe o mundo como ritmo: tudo se corresponde porque tudo tem ritmo e rima, por isso, é considerada a ciência das correspondências. Porém, é uma ciência que vive graças às diferenças. Pela analogia, a paisagem confusa da pluralidade e da heterogeneidade ordena-se e torna-se inteligível. A analogia implica não a unidade do mundo, mas sua pluralidade, não a identidade do homem, mas seu perpétuo dividir-se. A analogia é o reino da palavra como, essa ponte verbal que, sem suprimir, reconcilia as diferenças e as oposições. A poética da analogia consiste em conceber a criação literária como uma tradução; essa tradução é múltipla.

Em "Transbordamentos", a transcriação substitui o óbvio pela analogia.

\section{Conclusão}

Alinho meu pensamento ao de Deleuze e Guattari quando concebem "o rizoma como obra de arte" (30); sua construção como possibilidade de meditação. Os autores consideram a arte como realidade subjetiva. Tratar o pensamento como criação é uma forma de conceber a vida como processo de criação, uma "obra de arte" constantemente vinculada à produção de singularidades e diferenças.

Falar de "Transbordamentos" é falar de um entre-lugar, pois é no meio que as coisas emergem, acontecem (como um platô?). Assumir essa perspectiva é fazer emergir um espaçodevir - os interstícios, o limiar, o contingente, que abrem horizontes e ampliam 
possibilidades pela emergência do múltiplo, do polifônico, da diferença.

Esta obra é o resultado de um exercício disciplinado, atento e crítico que exigiu o domínio dos meios necessários para que o trabalho pudesse cumprir seus propósitos. Manifestou-se deixando fluir diferenças e semelhanças entre as várias possibilidades de leitura do texto literário que utiliza como suporte um sistema de signos plástico-icônicos. Buscou-se por meio do TRANS (transdisciplinar e transcriação) instaurar um jogo de analogias entre sistemas semióticos distintos.

A transcriação intersemiótica, como modo de leitura, proporcionou revitalizar Grande sertão: veredas estabelecendo novas relações entre texto literário, artes plásticas e filosofia. Neste processo, recortes pertinentes do texto original foram feitos com a tesoura nas mãos, conforme declara compagnon: "o essencial da leitura é o que eu recorto, o que eu ex-cito"(31).

Observou-se também que, pela transcriação, "Transbordamentos" gerou um imaginário próprio que pode ir além da imagem verbal, visual e tátil.

Entretanto, espera-se que a finalização deste trabalho não signifique um ponto de chegada, mas um ponto de partida para novas reflexões, principalmente no que diz respeito à possibilidade de a dinâmica transdisciplinar enriquecer e ampliar novos pontos de vista sobre pesquisas e produções plásticas dentro da universidade. 
Txt: Leituras Transdisciplinares de Telas e Textos, Belo Horizonte, n. 3, p. 30-48, 2006.

\begin{abstract}
The role of knowledge in our present society challenges professors who face an enormous quantity of information and technology. The webs of knowledge may offer strategies for the construction of knowledge within schools, besides being an opportunity for work with production and reading of images and texts, with the construction, appropriation of concepts whitin the cultural universe and curricular content.
\end{abstract}

Key-words: web of knowledge, text production, image reading.

\title{
Notas :
}

(1) Seminário Internacional Guimarães Rosa. Veredas de Rosa. Belo Horizonte: PUC-Minas, CESPUC, 2000. p. 690.

(2) DOMINGUES, 2005. p. 17.

(3) ASSMANN, 1998. p. 183.

(4) WEISFLOG, 1998. p. 2060.

(5) FOSTROWER, 1978. p. 51.

(6) CALVINO, 1984.

(7) IBOSI, 1986. p. 9.

(8) BARTHES, 1990.p. 165.

(9) Ibidem, p. 165.

(10) 0 BASBAUM, 1995. p. 382.

(11) WEISFLOG, 1998. p. 571.

(12) DICIONÁRIO UNIVERSAL DA LÍNGUA PORTUGUESA, 1993. p. 741 .

(13) MICHAELIS, p. 19.

(14) DELEUZE \& GUATTARI, 1995. p. 37. 
Txt: Leituras Transdisciplinares de Telas e Textos, Belo Horizonte, n. 3, p. 30-48, 2006.

(15) CAPRA, 1996. p. 80 .

(16) Ibidem, p. 80

(17) CALVINO, 2004. p. 121 .

(18) CAPRA, 1996. p. 89.

(19) MATURANA, 1994. p. 16.

(20) CALVINO, 2004.p. 122.

(21) DELEUZE \& GUATTARI, 1995. p. 33.

(22) Ibidem, p. 18 .

(23) Op. Cit, p. 32.

(24) Op. Cit, p. 23.

(25) BARTHES, 1990. p. 113.

(26) DEBRAY, 1994. p. 61.

(27) VALERY, 1991. p. 141.

(28) Ibidem, p. 141.

(29) PAZ, 1993. p. 98.

(30) DELEUZE \& GUATTARI, 1995. p. 144.

(31) COMPAGNON, 1996. p. 99.

\section{Bibliografia:}

ASSMANN, Hugo. Reencantar a educação: rumo à sociedade aprendente. Petrópolis: Vozes, 1998.

BASBAUM, Ricardo. Migração das palavras para a imagem. In: Gávea, Rio de Janeiro, $\mathrm{n}^{\circ}$ 13, set, 1995. p. 373-395. 
BENJAMIN, Walter. A tarefa do tradutor. Revista Humboldt, no 40, Munique, Bruckmann, 1979. p. 38-44. (trad. De Fernando Camacho).

BOSI, Alfredo. Reflexões sobre a arte. $2^{a}$ ed. São Paulo: Ática, 1986 .

CALVINO, Ítalo. Ditelo coi Nodi in collezione di Sabbia. (Tradução: Maria Lúcia de Resende Chaves). Itália: Garzanti, 1984 .

CALVINo, ítalo. Seis propostas para o próximo milênio. São Paulo: Companhia das Letras, 1990.

CAMPos, Haroldo de. Metalinguagens e outras metas. São Paulo: Perspectiva, 1993.

CAPRA, Fritjof. A teia da vida. São Paulo: Cultrix, 1996.

COMPAGNON, Antoine. o trabalho da citação. Belo Horizonte: Editora UFMG, 1996.

DEBRAY, Régis. Vida e morte da imagem. Petrópolis: Vozes, 1994 .

DELEUZE, G. et al. Mil Platôs: capitalismo e esquizofrenia, v.1. Rio de Janeiro: Ed. 34, 1995.

DERDYK, Edith. Linha de costura. São Paulo: Iluminuras, 1997.

Domingues, Ivan. Em busca do método. In: Conhecimento e transdisciplinaridade II - aspectos metodológicos. Belo Horizonte: Editora UFMG, 2004.

FOCILLON, Henri. A vida das formas - Elogio da mão. Lisboa: Edições 70, 1943.

LORENZ, Gunter. Diálogo com Guimarães Rosa. In: Coutinho, Eduardo (Org). Guimarães Rosa: Rio de Janeiro: Civilização Brasileira; Brasília: Instituto Nacional do Livro, 1983. 
Txt: Leituras Transdisciplinares de Telas e Textos, Belo Horizonte, n. 3, p. 30-48, 2006.

MATURANA, Humberto e VARELA Francisco. De máquinas e seres vivos - autopoiesis: a organização do vivo. Porto Alegre: Artes Médicas, 1994.

ostrower, Fayga. Criatividade e processos de criação. Petrópolis: Vozes, 1978.

1990 .

- Acasos e criação. Rio de Janeiro: Campus,

PAREISON, Luigi. Estética - teoria da formatividade. São Paulo: Martins Fontes, 1989.

PAZ, Octavio. Os filhos do barro. Rio de Janeiro: Nova Fronteira, 1986.

PLAZA, Júlio. Tradução intersemiótica. São Paulo: Perspectiva, 1987.

READ, Herbert. As origens da forma na arte. Rio de Janeiro: Zahar Editores, 1967.

ROSA, João Guimarães. Grande sertão: veredas. Rio de Janeiro: Nova Fronteira, 2001.

SANTAELLA, Lúcia. et al. Imagem: cognição, semiótica, mídia. São Paulo: Iluminuras, 1999.

Seminário Internacional Guimarães Rosa (1988: Belo Horizonte) Veredas de Rosa. - Belo Horizonte: PUC Minas, CESPUC, 2000 .

SILVEIRA, Paulo. A Página Violada. Da ternura à injúria na construção do livro- de-artista. Porto Alegre: Ed. UFRGS, 2001 .

SoUzA, Eneida Maria de. Traço crítico - ensaios. Belo Horizonte: Editora UFMG, 1993.

VALÉRY, Paul. Variedades. São Paulo: Iluminuras, 1991.

WEISFLOG, Walter (Ed.). Michaelis: moderno dicionário da língua português. São Paulo: Melhoramentos, 1998. 
Txt: Leituras Transdisciplinares de Telas e Textos, Belo Horizonte, n. 3, p. 30-48, 2006.

\section{REVISTA}

Revista do Instituto Arte das Américas. Vol.2, no 1. p. 148 .

\section{SITES}

http://www.artewebrasil.com.br/marcelo/livro-objeto.htm http://www.judaica.com.br/materias/020_04a10.htm 